\title{
Dual-Fuel-Electric Propulsion Machinery Concept on LNG Carriers
}

\section{Joško Dvornik, Srđan Dvornik}

Human efforts to devise optimum propulsion for their vessels are as old as the vessels themselves. Today these efforts are even more determined as modern shipping requires propulsion systems that are increasingly reliable, available, cost-efficient and able to meet high ecological criteria. The heat transfer towards liquefied gas stored in tanks results in boil-off during cargo handling or voyage. The rate of the evaporated gas amounts to $0.13 \%$ per day during the voyage of a fully loaded ship.

Steam turbines have been a dominant form of propulsion on liquefied natural gas - LNG carriers for over forty years. Until recently, the possibility of using boil-off gas as fuel for boilers has been the reason for installing steam plants as the only means of propulsion of LNG carriers. However, it has been proved that these plants are not sufficiently efficient due to adverse impacts on both emissions and the vessel's operating expenses. It has also been found out that dual-fuel-electric propulsion is the most effective alternative to steam. Shipping companies select electric propulsion primarily because it provides excellent manoeuvrability and increased availability, allows reduction of the machinery space and better arrangement of shipping capacity and, naturally, because of lower fuel costs. This paper discusses the newest technologies and the operation principle of the low-pressure four-stroke dual-fuel diesel engine, specifically the 12V50DF and 9L50DF types produced by Wärtsilä company, and the concept of the dual-fuel-electric propulsion for the new generation of LNG carriers.

\section{KEY WORDS}

$\sim$ LNG carriers

$\sim$ Boil-off gas

$\sim$ Dual-fuel engine

$\sim$ Electric propulsion

University of Split, Faculty of Maritime Studies, Split, Croatia e-mail: josko@pfst.hr

\section{INTRODUCTION}

Dual fuel diesel engines are the engines that can burn natural gas in addition to marine diesel oil or heavy fuel oil. In order to be efficient, such engines have to ensure stable combustion of gas fuel under any circumstances. Unlike liquid fuel which is self-ignited under compression in the cylinder, methane - the main component of the natural gas-cannot be self-ignited. Therefore its ignition is triggered by liquid fuel. The observed machinery comprises four main diesel enginesgenerators. Two Wärtsilä 12V50DF engines can develop 11.400 $\mathrm{kW}$ at maximum continuous rating (MCR) in diesel or gas mode, whereas two Wärtsilä 9L50DF engines have an output of $8.550 \mathrm{~kW}$ MCR in diesel or gas mode, according to (Machinery operating manual, 2009).

All engines are designed to run on boil-off gas from cargo tanks or marine grade diesel oil MDO from daily service tanks. Although the two fuel types have different density and calorific value, the engines can operate efficiently both on gas and MDO and develop the same output in both modes.

Boil-off gas (BOG) from cargo tanks is essentially a good fuel for combustion within the engine cylinders but due attention has to be paid to the gas contents, in particular the content of nitrogen in the natural gas as, unlike pure methane, nitrogen effectively reduces the gas energy contents.

The amount of nitrogen in BOG may amount up to $30 \%$ in volume at the beginning of the loaded ship voyage. The engines and their fuel control systems are designed to adjust to all conditions and to enable each engine to be running on gas at their normal rating without evaporisation, according to (Machinery operating manual, 2009).

The engines are also fully capable of switching over from one fuel to another during operation and when running under load, without interrupting the electric power supply. Also, these engines are identical with regard to their components such as pistons, valves, injectors, etc. It is possible to choose nine 
or twelve cylinder engines, which allows for flexibility when installing the engines, in line with the supply demand.

The Wärtsilä engine control system 8000 (WECS 8000) monitors and controls the safety of operation, engine speed, fuel control and other relevant automated functions. Gas combustion gives rise to many issues regarding safety and protection and these issues are carefully addressed when designing and operating the engine. Separate systems are required for liquid and gas fuels, and due to low ignition level of natural gas, it is necessary to inject a small amount of pilot fuel to produce flame for igniting natural gas in the cylinder, according to (Machinery operating manual, 2009).
In gas mode, gas is admitted into the cylinder together with the combustion air during the intake stroke. It is mixed with the air inside the inlet channel in the cylinder head. The mixture of gas and air is then compressed and ignited by a small quantity of diesel pilot fuel at the end of the compression stroke, see Figure 1, according to (Norrgärd, 2006; Guidelines for Dual Fuel Diesel Engines, 2008; Kosomaa, 2002). The pilot fuel injection timing is closely regulated to provide flame for gas ignition at the correct moment. Gas ignites and burns, pushing the piston downwards as in a conventional diesel engine where power is developed by liquid fuel combustion.
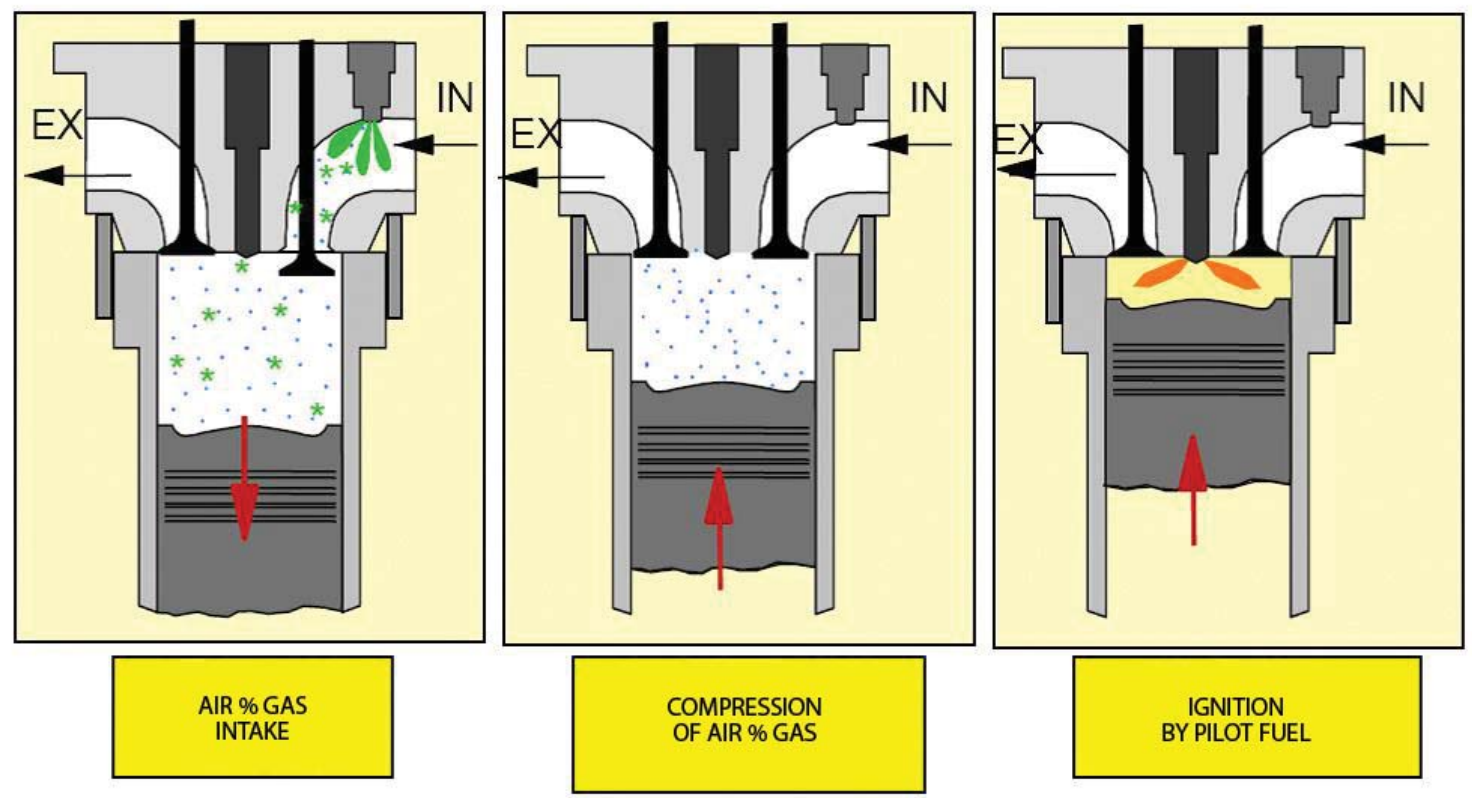

Figure 1.

Gas mode.

\section{OPERATION PRINCIPLE}

Wärtsilä 12V50DF and 9L50DF engines drive generators to supply electricity for all ship systems including the main propulsion plant. The latter employs two electric motors driving a fixed-pitch propeller via a reduction gearbox. Figure 2, according to (Machinery operating manual, 2009), shows a simplified diagram of the electric propulsion system for the new generation of LNG carriers.
The engines can operate in diesel mode or in gas mode: they can not run in both modes, using BOG and MDO at the same time, except for a short moment when using pilot fuel while running on gas. Starting up of the engine is always performed by using diesel fuel, see Figure 3, according to (Norrgärd, 2006; Guidelines for Dual Fuel Diesel Engines, 2008; Kosomaa, 2002). 


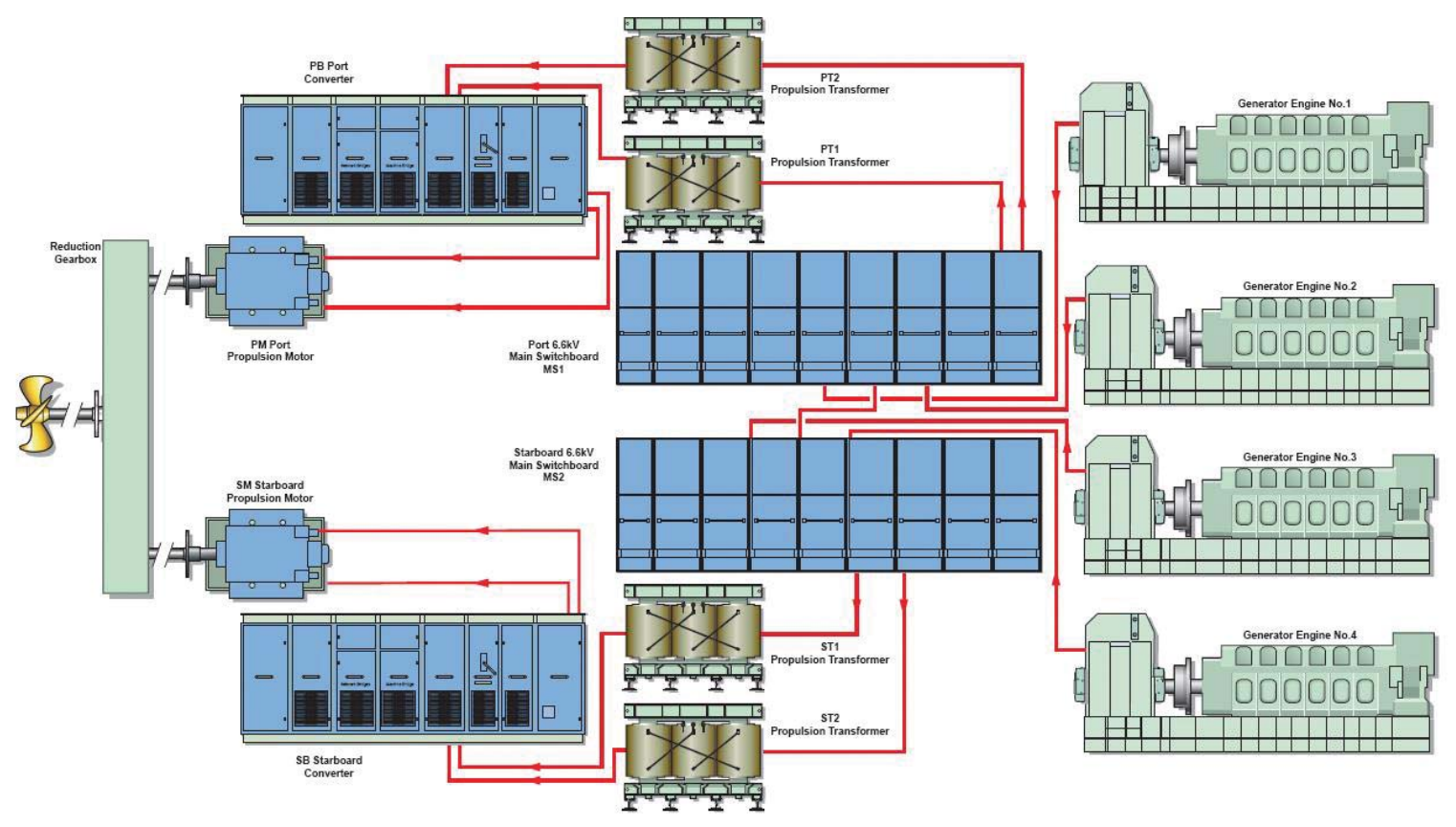

Figure 2.

Simplified diagram of the electric propulsion system on LNG carriers.
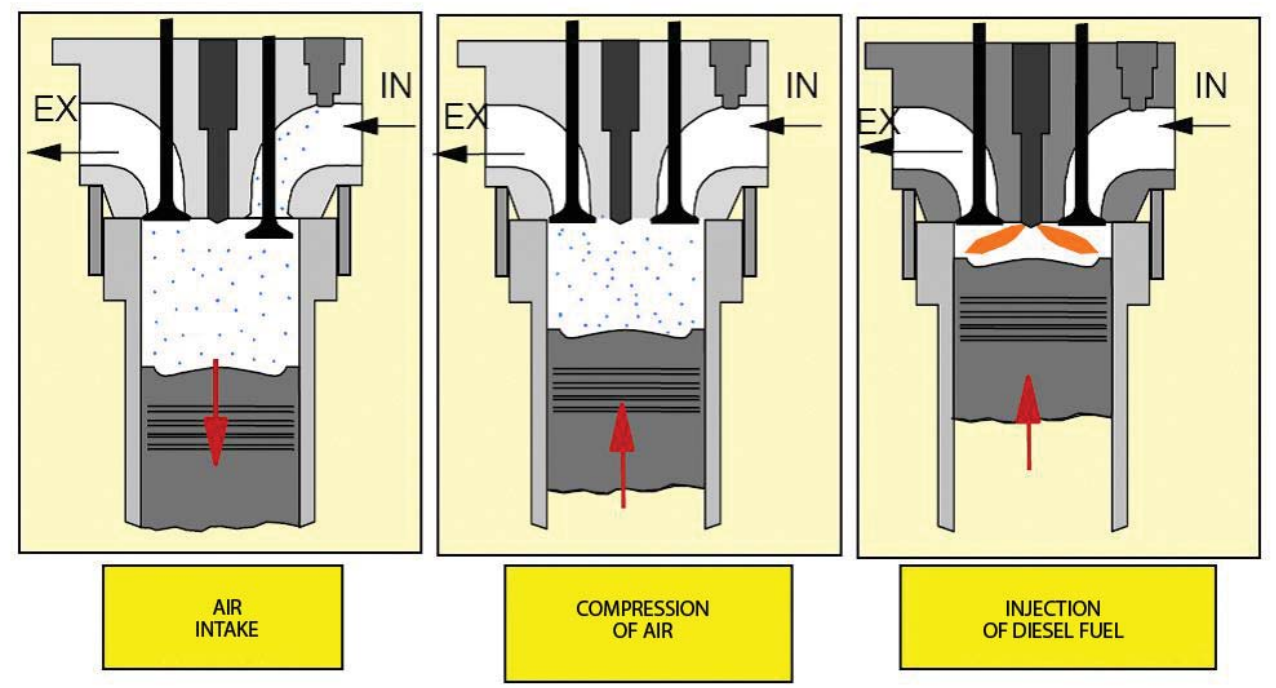

Figure 3.

Diesel mode. 


\subsection{Diesel fuel supply mode}

In diesel mode, dual-fuel engines act like normal diesel engines using conventional high-pressure fuel injection pumps and injectors in each cylinder head. The high-pressure fuel pump is operated by the camshaft and the fuel injector operates normally by pressure action on the needle valve, see Figure 4, according to (Machinery operating manual, 2009; Olander, 2006).

The cylinder head of the Wärtsilä 50DF engine houses a centrally placed dual-needle fuel injector. The larger needle is used for injecting diesel, whereas the smaller one is used for injecting pilot fuel when the engine is in the gas mode. Pilot fuel injection is controlled electronically, while diesel injection in diesel mode is controlled in a hydraulic-mechanical way by means of the high-pressure fuel pump, see Figure 5, according to (Machinery operating manual, 2009; Olander, 2006).

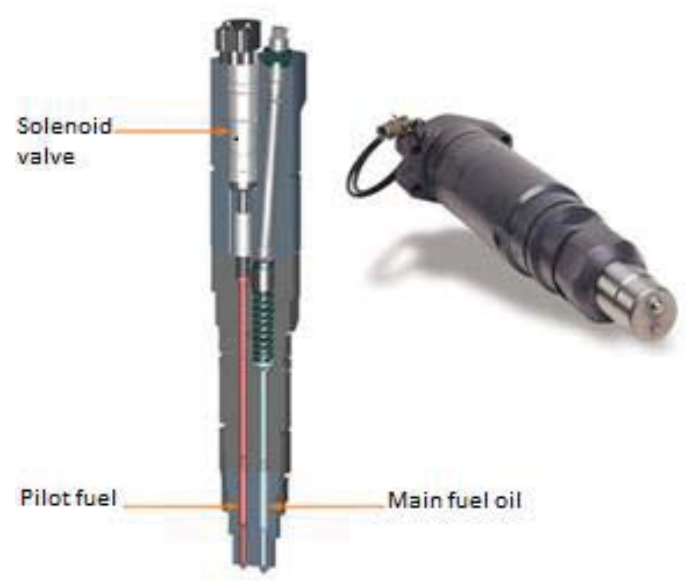

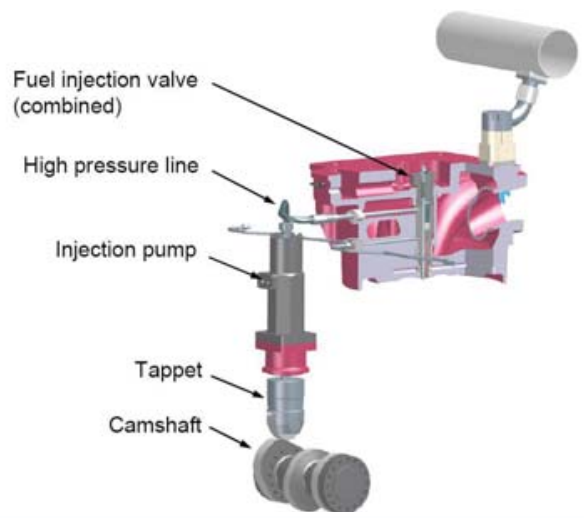

Figure 4

Conventional fuel injection system.

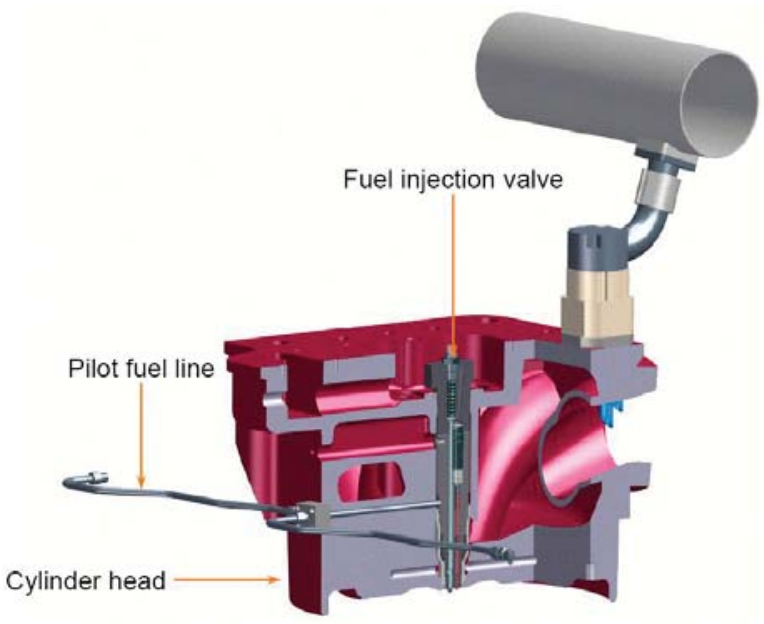

Figure 5.

Diesel fuel injector and cylinder head.

The liquid fuel supply system consists of two parts: the system for supplying and injecting marine diesel oil (MDO) or heavy fuel oil (HFO) is separated from the pilot fuel system. Pilot fuel is compressed at the required pressure by the pump unit that includes pilot fuel filters, pressure regulator and engine driven radial reciprocating pump.

Pilot fuel is then conveyed through the common rail system to the injector in each cylinder head. It is injected at 900 [bar]. Metering and timing of the injection are electronically controlled, see Figure 6, according to (Machinery operating manual, 2009; Norrgärd, 2006).
The pilot fuel system remains switched on even when the engine runs on liquid fuel in order to prevent clogging of nozzles due to carbon deposits produced during the combustion process. Excess fuel is returned to the mixing tank and to the circulating pump inlet. The fuel return system is fitted with the cooler for reducing the temperature of the diesel that is warmed up by passing through the fuel system, see Figure 7, according to (Machinery operating manual, 2009). 


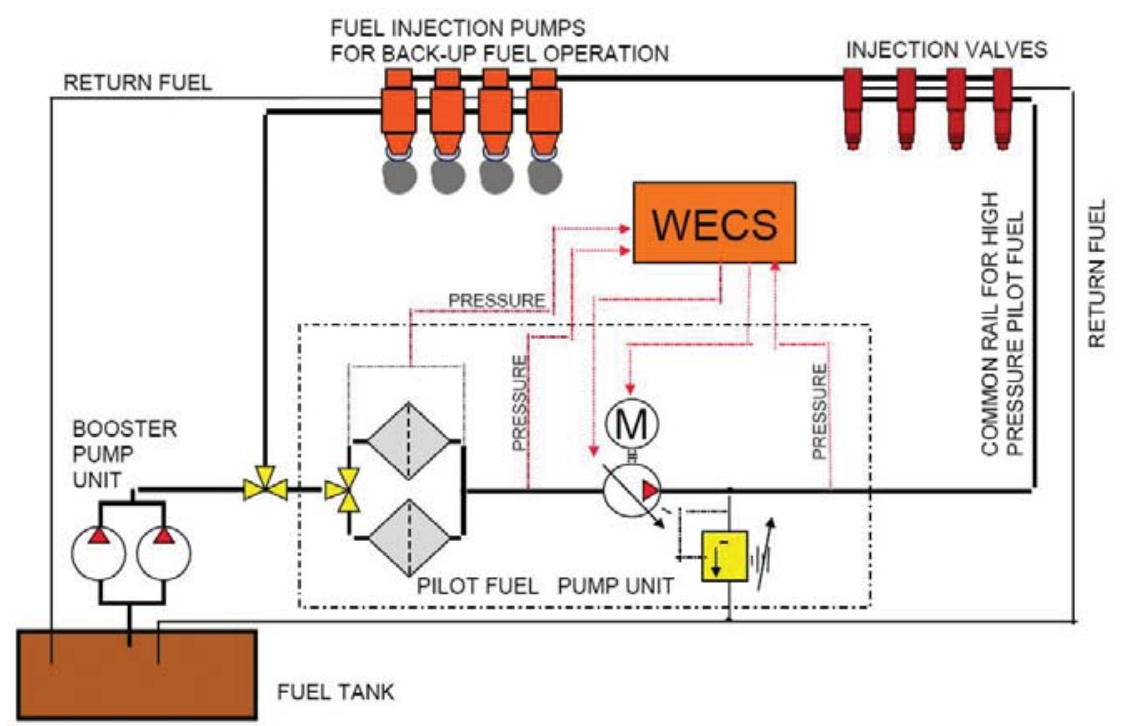

Figure 6.

Main fuel and pilot fuel supply control.
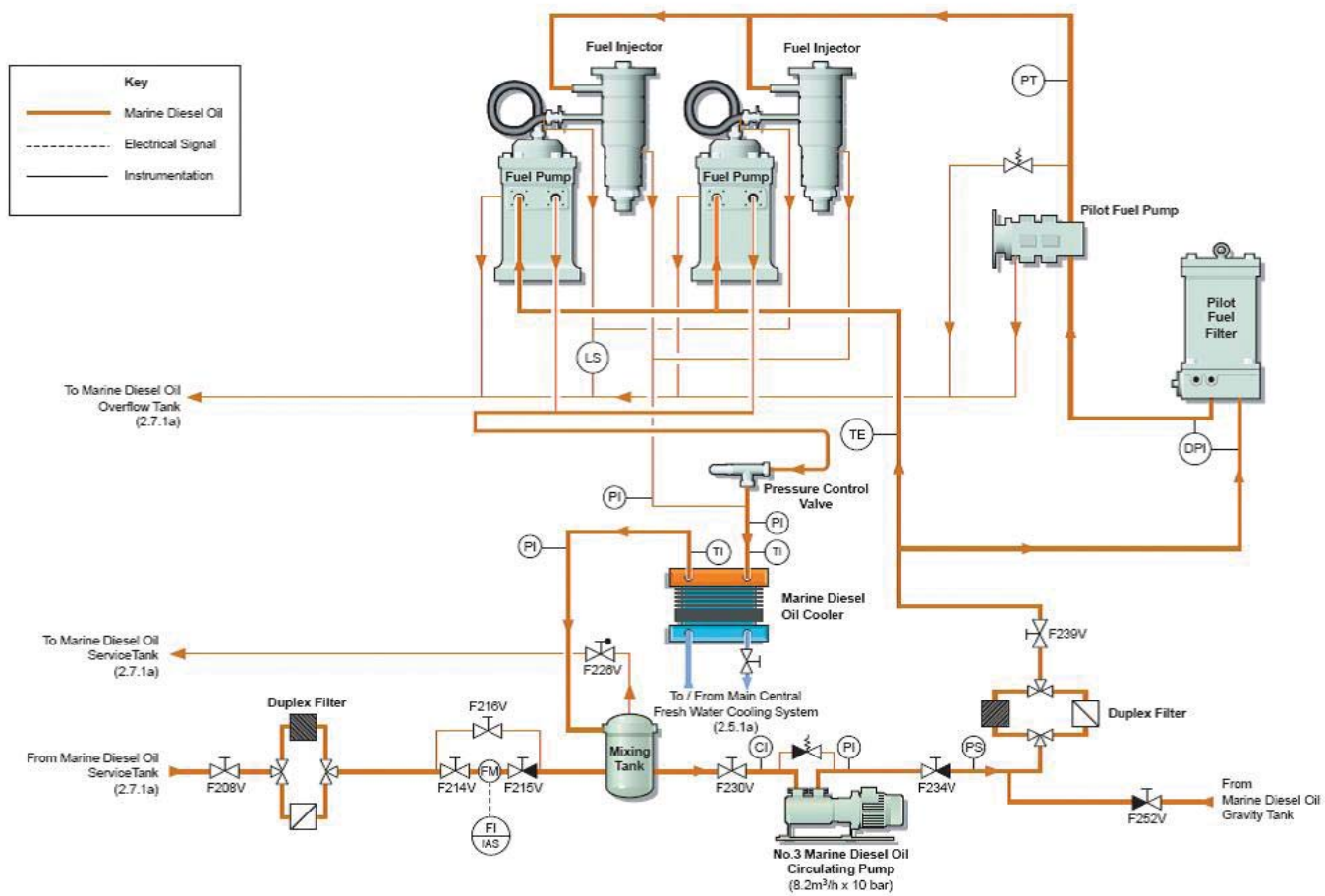

Figure 7.

Diesel oil and pilot fuel supply system. 
Individually controlled solenoid valves of pilot fuel ensure optimum timing and duration of fuel injection while the engine is in gas mode. As the amount of NOx emission largely depends on the quantity of pilot fuel, this design ensures a very low NOx emission while using the stable and reliable system of igniting a lean, premixed air-gas mixture in the engine combustion chambers.

\subsection{Gas supply mode}

The evaporated gas from the cargo tanks is conveyed under pressure through the boil-off heater and natural boil-off mist separator (NBO) to the engine by means of centrifugal twostage LD (low duty) compressors installed in the maindeck cargo handling room, at nominal temperature of $30^{\circ} \mathrm{C}$, according to (Machinery operating manual, 2009).
When the boil-off gas leaves the deck area at regular pressure of 6.3 [bar], it can be burned either in the gas combustion unit or the main engines. If one wishes to put the boil-off gas system into service, the gas is burnt until stable conditions for gas operation are reached and then the gas can be transferred for the use in engines.

Prior to entering the engine, BOG passes through the gas valve unit (GVU) which consists of a filter, temperature sensor, pressure sensor, pressure regulating valve, two safety tripping valves, and three remotely-controlled ventilation regulating valves, see Figure 8 , according to (Machinery operating manual, 2009; Norrgärd, 2006).

The outlet gas pressure is controlled by WECS 8000 (Wärtsilä engine control system 8000) in line with the engine load and ambient state. The BOG pressure at the engine inlet is 5.1 bar.

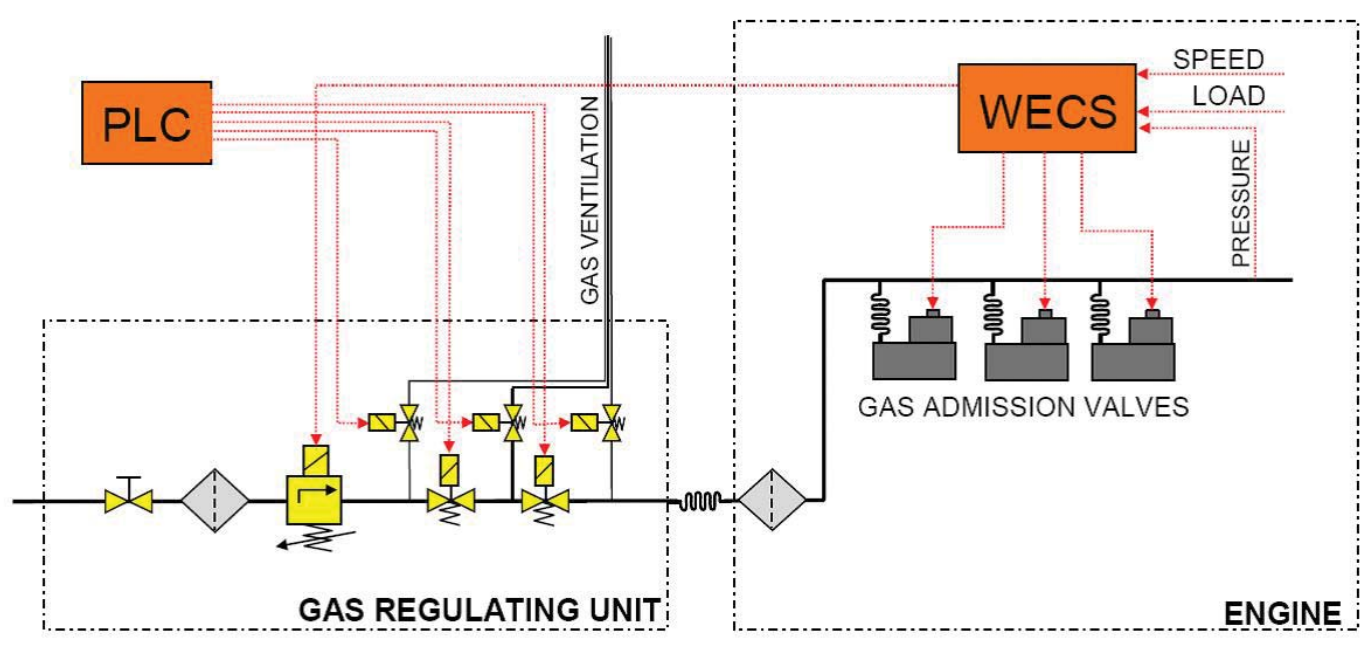

Figure 8.

Gas fuel supply control.

Safety and ventilation valves are solenoid electromagnetic valves and the control is carried out by the external integrated automation system (IAS), whereas the pressure regulating valve is directly operated by WECS 8000 controller. During the operations of starting and stopping the engine, the control of safety valves and ventilation valves communicates between WECS and IAS systems, including the checking of dribbling/leaking of valves prior to starting each engine, according to (Machinery operating manual, 2009).

Reference pressure of the gas supply is dependent on the engine load and is calculated by the WECS 8000 control module.

The electric signal of the reference pressure is forwarded to the pressure regulating valve. The real pressure in the engine is measured and compared with the reference pressure. If the deviation is excessive, an alarm will be sounded, and if the deviation continues to increase the safety valve will be immediately closed and the supply of gas to the engine will be interrupted. Upon passing through the GVU, gas enters the common rail manifold extending along the engine and is distributed through individual cylinder lines to the gas admission valve on each cylinder head, see Figure 9, according to (Olander, 2006). The valves are controlled by WECS 8000 system that regulates the amount of gas entering each cylinder, according to (Machinery operating manual, 2009). 


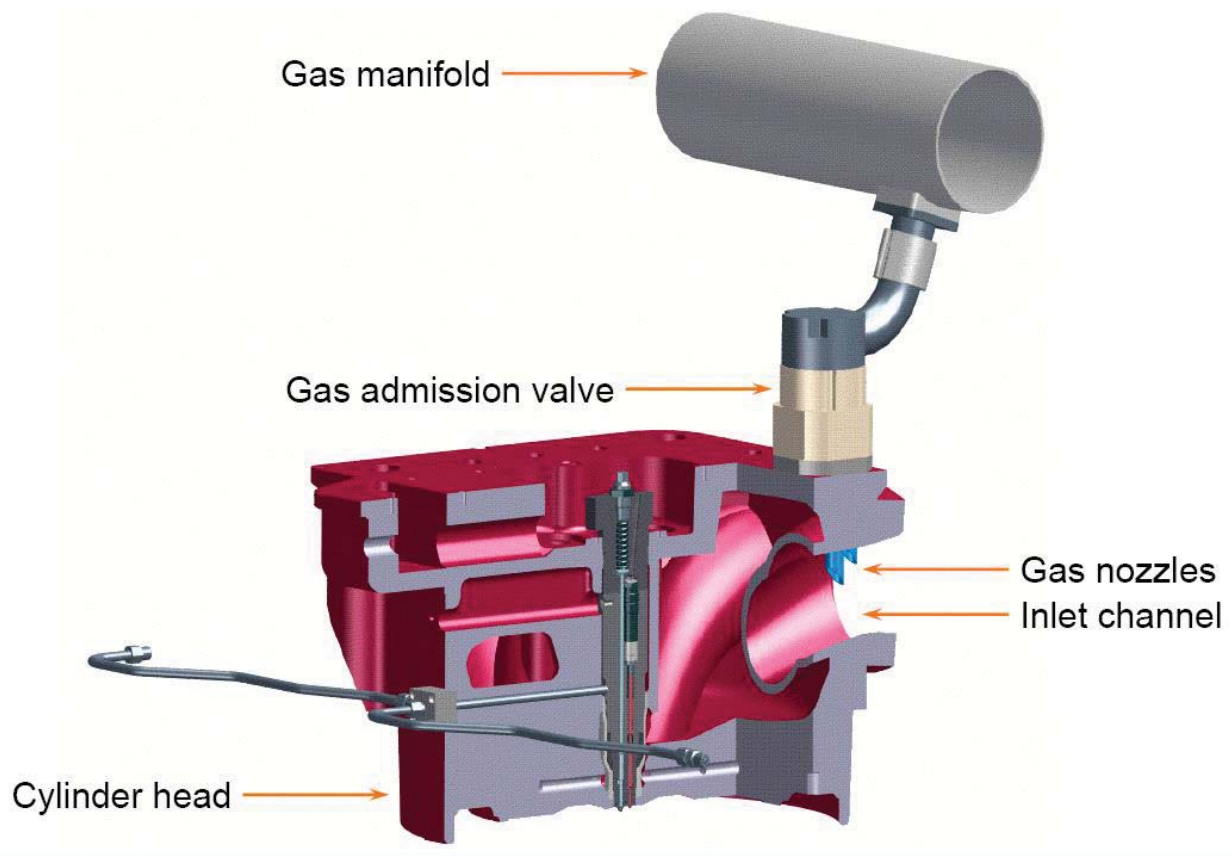

Figure 9.

Gas fuel supply system.

The gas supply line may feature a single wall - inside the valve unit (single wall piping) or a double wall - inside the engine room (double wall piping). The annular space in double wall piping (a pipe inside a pipe) is ventilated by air supplied either from the engine room or via special pipeline outside the engine room. The use of double wall piping fitted with adequate ventilation ensures maximum safety in the event of gas leakage, see Figure 10, according to (Olander, 2006).

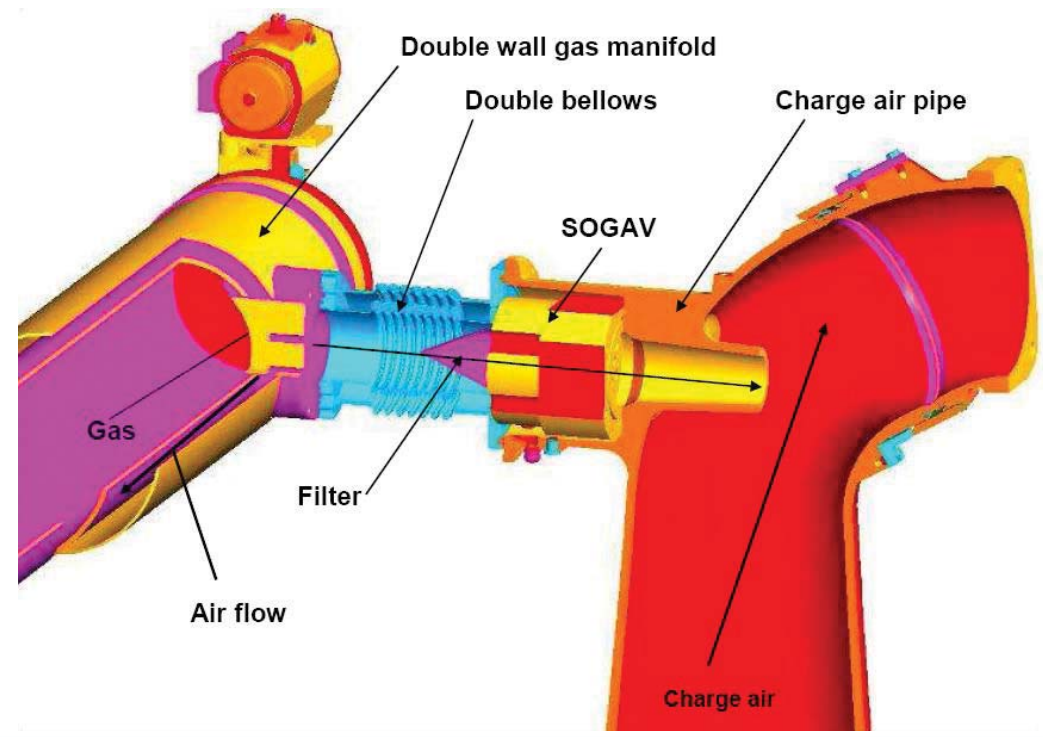

Figure 10.

Double wall piping in Wärtsilä 50DF. 


\subsection{Gas valve and the control of gas-air ratio}

In Wärtsilä DF engines, boil-off gas is admitted to the cylinder through the electronically controlled gas admission valve which meters the gas into the charge air pipe immediately before the cylinder's inlet valve. The gas amount and pressure are regulated by a sophisticated electronic system for each cylinder separately. Opening of the gas admission valve is independent from opening of the inlet valve, so that during the scavenge process there is no risk of potential loss of gas fuel through the exhaust system, according to (Machinery operating manual, 2009).

The amount of the main and pilot fuel is controlled in the same way. Optimisation of the engine operation is performed on the basis of input data such as revolutions per minute (rpm), load, air/fuel ratio etc., which results in better thermal efficiency and reduced harmful emissions, in particular NOx, see Figure 11, according to (Norrgärd, 2006; Olander, 2006).
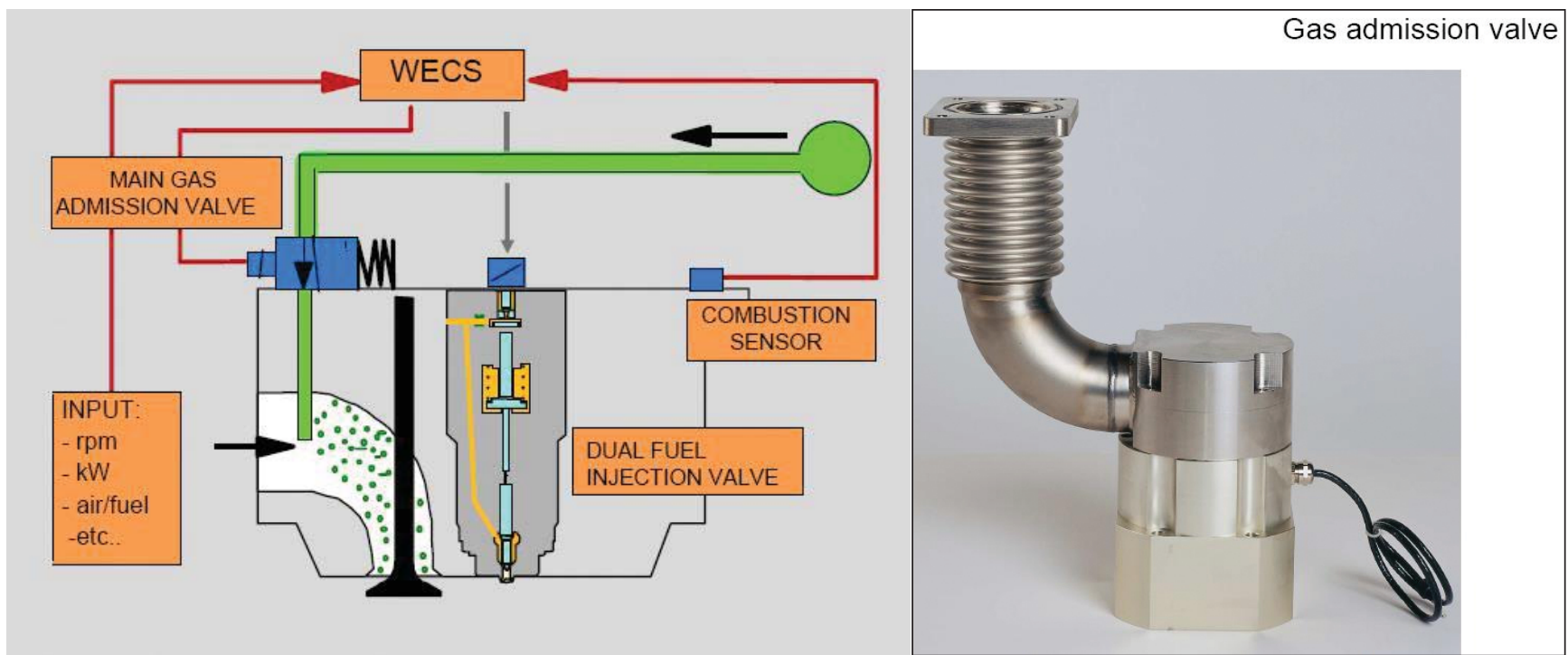

Figure 11.

Cylinder control principle.

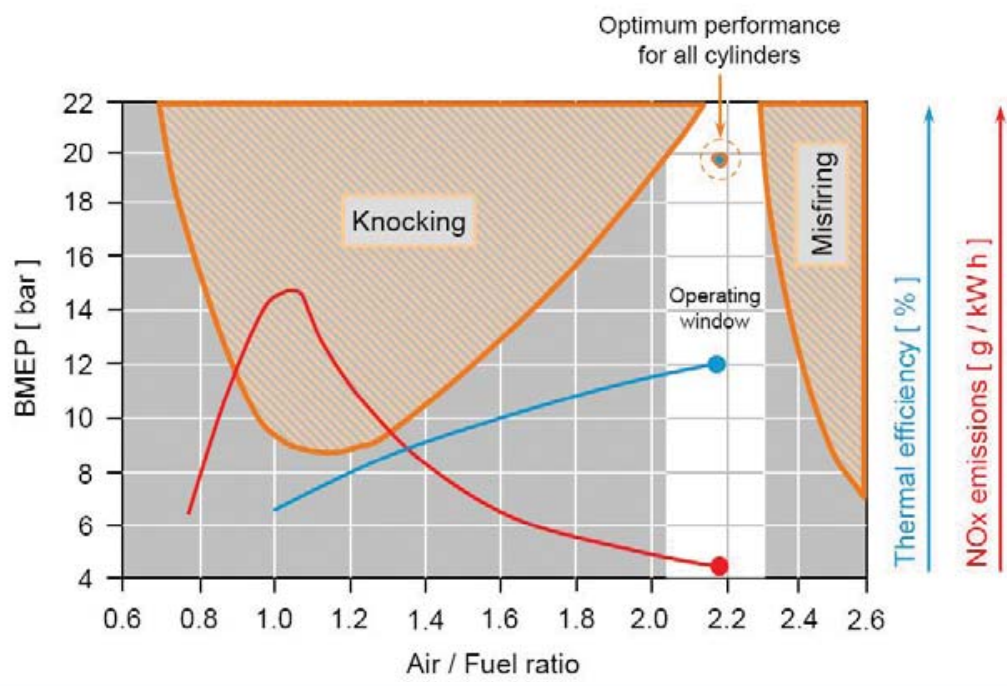

Figure 12.

Optimum combustion gas/air ratio. 
ratio, and amount and duration of pilot fuel injection. Gaseous fuel pressure, amount of fuel flow and pilot fuel injection timing are calculated depending on external control algorithms. The main control module uses the information provided by all other modules and sends reference signals for cylinder control modules.
Engine starting and stopping sequences, safety system and change in operation mode (diesel/gas mode) are also automatically controlled. If any input signal shows an incorrect value, the control system will give alarm, see Figure 15, according to (Olander, 2006; Henry, 2012).

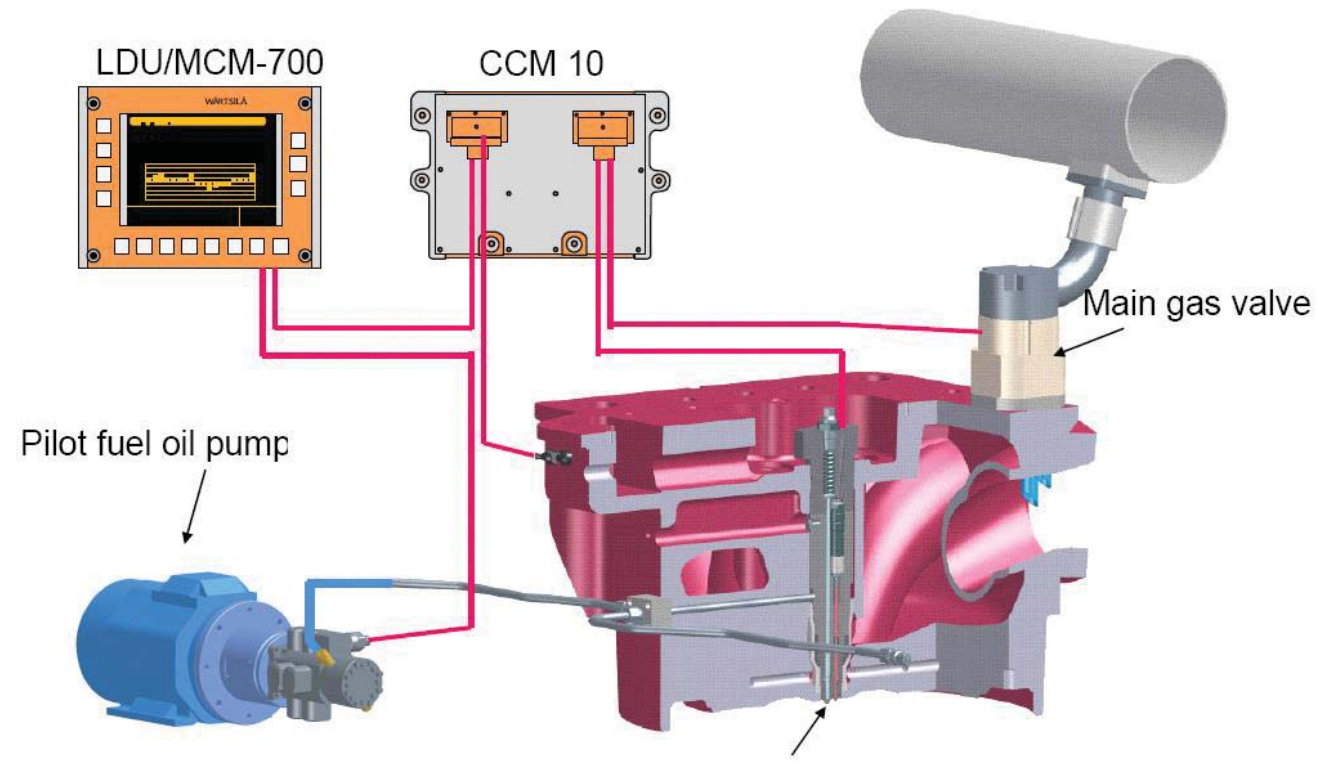

Pilot fuel injection valve

Figure 15.

Cylinder control principle.

The amount of gas admitted into the cylinder is controlled by separate gas admission valves on each cylinder. The valves are controlled by CCM-10 (cylinder control module). The latter controls the amount of gaseous fuel flow and pilot fuel injection by using high-energy output PWM (pulse width modulation) signals.

Each module gives signals for three fuel flow regulation valves and for three pilot fuel injection valves. The modules calculate the appropriate injection timing and duration, depending on the reference values provided by the main control module.

In order to provide control signals for pilot fuel injection at the appropriate angular position of the crankshaft, the modules have to obtain accurate information from the speed sensor and engine phase sensor, according to (Machinery operating manual, 2009).

The amount of the admitted gas depends on the supplied gas pressure and the time during which the main solenoid gas valve is open. The gas admission moment is controlled by opening the gas valve and the position of the piston with regard to the top dead centre for each cylinder. This results in the optimisation of air/gas mixture and enables good combustion. The WECS 8000 system uses the pre-set values which have been calculated for the purpose of optimising the air/gas mixture during engine operation.

In the WECS 8000 system, all sensors are connected to the CCM-10 modules (whose number depends on the number of cylinders) and two main control modules MCM-700.

One of the main control modules is used exclusively for processing the data provided by the sensors. The signals from the sensors are filtered, linearised and grouped. The system also checks errors in signals, i.e. errors in the sensors or network will always be detected and transformed into alarms. All measured values are sent to the machinery units and the information is transferred through CNA-buses or the communication protocol Modbus TCP/IP. In case of engine malfunction, the sensors will detect the occurrence and the WECS system will automatically perform adequate protection action, in order to ensure safe operation of the engine, according to (Machinery operating manual, 2009).

Figure 16, according to (Henry, 2012), shows the fuel system components in the cylinder head. 


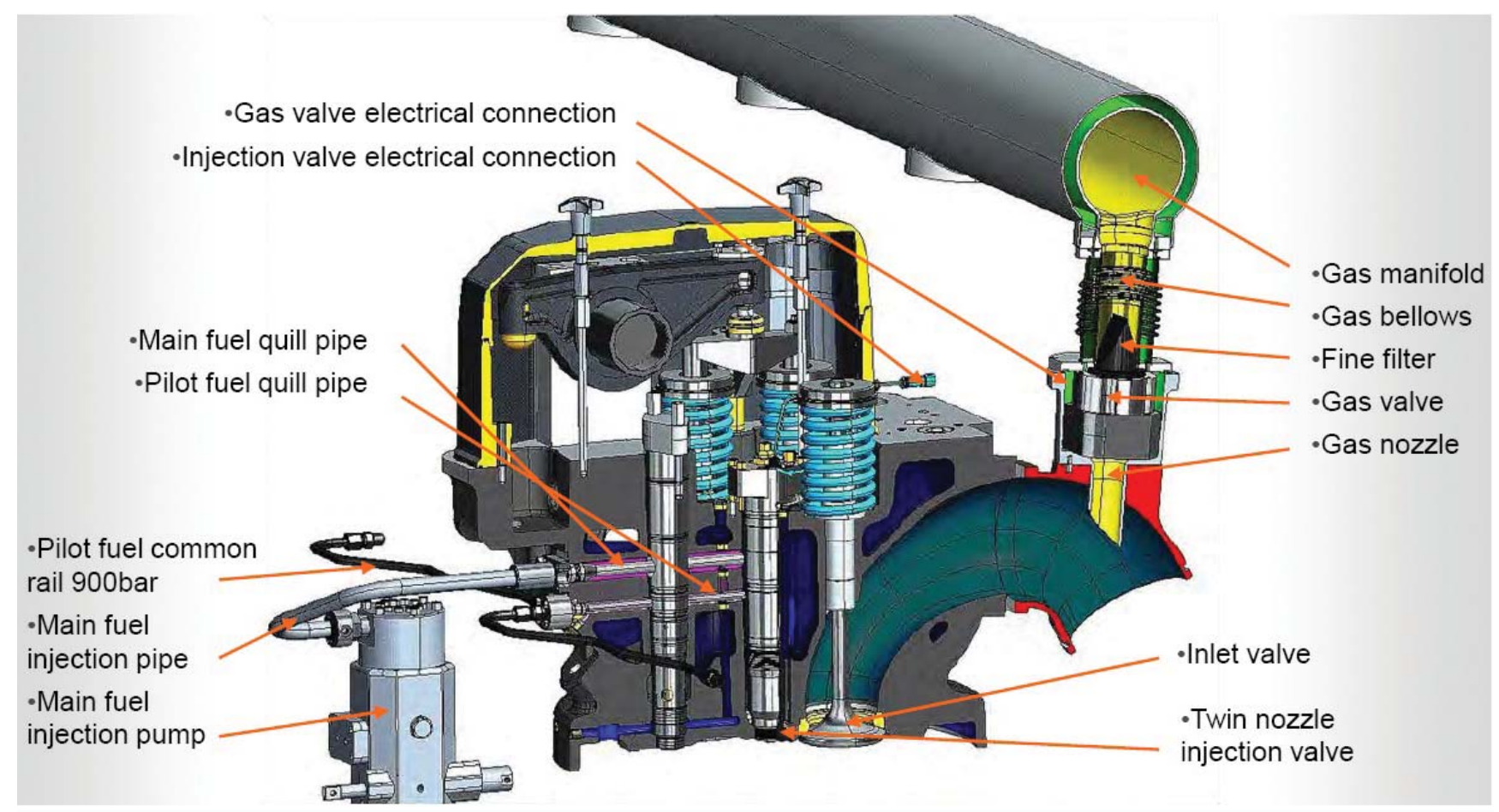

Figure 16.

Fuel system components in the cylinder head.

\section{CONCLUSION}

Dual-fuel engines successfully meet the requirements of the LNG transport when they are combined with electric propulsion. After a comprehensive comparison of all available alternatives for propelling LNG carriers, the concept of the dual-fuel-electric propulsion has clearly proved to be the optimum option, both from the commercial and technological points of view.

Due to losses in generators, transformers, converters, electric motors, gearboxes and shafts, the dual-fuel electric concept achieves the thermal efficiency of about $43 \%$. However, this compares very favourably with the overall thermal efficiency of the steam turbine drive system which is less than $30 \%$. Dualfuel electric propulsion systems have ceased the domination of steam turbine propulsion systems in LNG shipping, according to (Thijssen, 2006a; Thijssen, 2006b).

This concept's performances surpass the steam turbine concept in the areas of cost-efficiency and redundancy, while providing equal safety, reliability and maintenance features.

Although the maintenance requirements are higher than in steam turbines, this does not reduce the overall cost-efficiency of the vessel.

If compared to diesel engines, the dual-fuel electric concept offers better cost-efficiency, redundancy and maintenance features. Emissions of dual-fuel-electric installations are generally lower than those of steam turbine (as a result of higher efficiency) and diesel engine installations (due to cleaner fuel), according to (Thijssen, 2006a).

Reduced harmful emissions and considerably increased safety of the vessels featuring electric propulsion, in addition to increasingly strict regulations in certain navigation areas and regarding certain types of dangerous cargo will continue to limit the exploitation area of the vessels fitted with diesel-mechanical propulsion.

Increased fuel prices caused by the exploitation of oil reserves and large increase in demand, as a result of rapid industrial and economic development of China and other economies in the Far East, will result in higher fuel costs and the likely reduction in the navigation speed. In such a scenario, the dual-fuel electric propulsion will gain a competitive advantage over the conventional diesel-mechanical plant due to a considerable higher fuel consumption of the latter concept.

\section{REFERENCES}

Guidelines for Dual Fuel Diesel Engines, (2008), Chiba: Nippon Kaiji Kyokai Reasearch institute.

Henry, J. M., (2012), Retrofit Moteur Diesel Wärtsilä en Dual fuel, ENSM Marseille, Wärtsilä, France, available at: http://www.supmaritime.fr/pdf/Retrofit_moteur_ diesel_Wartsila.pdf, [accessed 15 January 2014.]. 
Kosomaa, J., (2002), The DF-Electric LNG Carrier Concept, GASTECH Qatar, available at: http://www.witherbyseamanship.com/the-df-electric-Ing-carrier-conceptdownloadable-product.html, [accessed 13 December 2013.].

Machinery operating manual, (2009), M/V Tangguh Sago, Teekay, Samsung Heavy Industries Co. Ltd., S. Korea.

Norrgärd, J., (2006), Wärtsilä 32 DF gas engine conversion, Engine Technology.

Olander, K., (2006), Dual-fuel-electric for LNGC, Wärtsilä, Korea, available at: http://

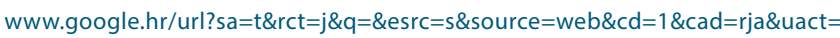
8\&ved=0CBoQFjAA\&url=http\%3A\%2F\%2Fwww.wartsila-hyundai.com\%2Ffiledo wn\%3Falias\%3Dadpds\%26file\%3DWartsila\%252B50\%252BDF\%252BDual\%252B fuel\%252Bengine $\% 252$ Breference $\% 252$ Bfor\%252BLNGC\%252B04\%252B01\%25 2B07\%252Bppt.pdf\&ei=SrEuVP_BHsW9PbS7gEA\&usg=AFQjCNEH5q4yyGMk4z1 na sYb-7_4XVJJKA, [accessed 15 January 2014.].
Paananen, J., (2007), LNG fuelled ships and auxiliaries, Storage and Transport Applications for Future Energy Sources (STAFFES) Workshop, Rostock, Germany, October 25.

Stenhede, T., (2006), Wärtsilä Power Plants, KTH/Engine Technology, available at: http://www.energy.kth.se/courses/4a1626/ahpt2006/comb1.pdf, [accessed 20 December 2013.].

Thijssen, B., (2006a), Dual-Fuel-Electric LNG Carrier Propulsion, Wärtsilä, Finland.

Thijssen, B., (2006b), Efficient and environmentally friendly machinery systems for LNG carriers, Wärtsilä, Finland. 